\title{
Characterization of the oestrous cycle and mating season of squirrel monkeys from copulatory behaviour
}

\author{
Margo I. Wilson* \\ Department of Psychology, University of Toronto, Toronto, Ontario, Canada
}

\begin{abstract}
Summary. Observations of the behaviour of squirrel monkeys, including 8 oppositesex pairs during daily $30-\mathrm{min}$ social encounters and 2 mixed-sex permanent groups during daily 30 -min observation sessions, over a 14-month period were used to determine the periodicity of the oestrous cycle and annual mating season. The median and modal length of the oestrous cycle was 8 days, within which copulations were limited to a 1-2 day period. In a cyclic female, plasma progesterone levels over a 24-day period dropped from $85-151 \mathrm{ng} / \mathrm{ml}$ to $25 \mathrm{ng} / \mathrm{ml} 2$ days before oestrus. In non-cyclic females plasma progesterone values were $<15.4 \mathrm{ng} / \mathrm{ml}$. Males exhibited a $6.8-19.7$ week 'season' of copulation and ejaculation. The onset of this 'mating season' in August coincided with the annual peak in male body weight (the 'fatted male' phenomenon).
\end{abstract}

\section{Introduction}

Squirrel monkeys appear to have a relatively discrete 3-month breeding season in their native habitats of Central and South America (Thorington, 1968; Baldwin \& Baldwin, 1971; Klein, 1974), within a troop transplanted to Florida (DuMond \& Hutchinson, 1967; Baldwin, 1968, 1970), and under captive conditions (Latta, Hopf \& Ploog, 1967; Rosenblum, 1968; Clewe, 1969; Hutchinson, 1970; Travis \& Holmes, 1974). This seasonal breeding was indicated by seasonality of births, spermatogenesis in testicular biopsies, increased body size of males ('fatted male' phenomenon), and incidental observations of copulation.

The length of the oestrous cycle is, however, undecided. Reports based solely on vaginal cytology have been variable, giving cycle lengths of 7-28 days (Denniston, 1964; Lang, 1967; Rosenblum, Nathan, Nelson \& Kaufman, 1967; Hutchinson, 1970; Srivastava, Cavazos \& Lucas, 1970; Travis \& Holmes, 1974). A male was seen to mount one female during 3 of 4 oestrous periods at 10-13 day intervals (Travis \& Holmes, 1974), but Rosenblum et al. (1967) found spermatozoa in vaginal smears every 7-9 days, Latta et al. (1967) noted receptive behaviour of a female at 7-8 day intervals, and Clewe (1969) observed mating every 5 or 6 days for up to 9 weeks when males were permitted access to groups of females for 30 min each day.

Copulation in squirrel monkeys has been observed (Rosenblum, 1968; Clewe, 1969; Travis \& Holmes, 1974), but only a small number of copulatory sequences have been described (Latta et al., 1967; Baldwin, 1968).

In the present study, observations were made for 14 months on the behaviour of 8 opposite-sex pairs of squirrel monkeys during daily 30-min social encounters, and on the behaviour of two groups of squirrel monkeys of mixed sex during daily 30 -min observation sessions.

\section{Materials and Methods}

Six adult male ('fatted' body weight: $1000-1250 \mathrm{~g}$ ) and 9 adult female (body weight: $540-578 \mathrm{~g}$ ) wild-reared squirrel monkeys (Saimiri sciureus) were obtained directly from Iquitos, Peru, 3 months before the study began. The oviducts of each female were ligated under anaesthesia to prevent conception; the operation was not successful for female No. 44 (see below).

*Present address: Department of Psychology, University of California, Riverside, California 92502, U.S.A. 
Four males (Nos 68, 62, 64 and 66) were housed individually $(46 \times 51 \times 56 \mathrm{~cm}$ cages: Harford Metal Products, Aberdeen, Maryland). Four females (Nos 50, 54, 51 and 55) were housed as singlesex pairs $(61 \times 76 \times 102 \mathrm{~cm}$ cages: Harford Metal Products $)$ and were each 'pair-tested' with a male each day during 30-min social encounters. The other animals formed two resident groups in $60 \times 90 \times 120 \mathrm{~cm}$ cages with a Plexiglas front wall: Group A consisted of Male 57 with Females 48 or 4 and 45 (Female 48 was separated from the group on 1 February 1974 because of poor health and was replaced by Female 4 on 3 July 1974) and Group B comprised Male 59 and Females 44 and 53. Female 44 was separated from Group B because of an eye infection from 1-21 January 1974. This same female gave birth to a male infant on 23 May 1974, and both mother and infant remained within the group.

Artificial lighting was maintained for $12 \mathrm{~h}$ each day from $07.00 \mathrm{~h}$. The ambient temperature ranged between 22 and $27^{\circ} \mathrm{C}\left(24.4 \pm 0.1\right.$ (S.E.M.) $\left.{ }^{\circ} \mathrm{C}\right)$ and the relative humidity between 33 and $91 \%(55 \cdot 3 \pm 0.4 \%)$. The animals were fed twice daily with primate biscuits (Teklad Mills, Missouri) and a supplement of fresh fruit and vitamins (Paltone: Pitman-Moore Inc., Titusville, New Jersey). Water was always available.

\section{Behavioural tests}

Males $68,62,64$ or 66 were each placed with one female for 30 min every day. Males 68 and 62 were paired with Females 50 and 54 on alternate days; and Males 64 and 66 were similarly paired with Females 51 and 55. The social encounters took place in $60 \times 90 \times 120 \mathrm{~cm}$ cages with a Plexiglas front wall in a room separate from the main colony. The animals were transferred to the testing cage by small carrying boxes which they readily entered. Groups A and B were observed in their home cages for $30 \mathrm{~min}$ each day. All observations were made from behind one-way glass tilted to avoid any reflections. All aspects of social behaviour were recorded in notation form for consecutive 1-min intervals, but in this paper only details of copulatory behaviour are described.

In the squirrel monkey, copulation consists of a series of mounts with rapid shallow pelvic thrusts without intromission, and slow deep, more regular thrusting movements with intromission, terminating in ejaculation (Latta et al., 1967; Hopf, Hartmann-Wiesner, Kühlmorgen \& Mayer, 1974). Mounting attempts, with or without pelvic thrusting, consisted of the male clasping the female's waist with both hands. A rapid withdrawal from the grip of the male constituted a refusal by the female. The occurrence of ejaculation was confirmed by the presence of spermatozoa in the vaginal smear taken immediately after the encounter.

Observations were made for $30 \mathrm{~min}$ between 08.00 and $12.00 \mathrm{~h}$ on 5-7 days per week from 19 November 1973 to 31 January 1975, making a total of 1493 30-min social encounters for the 4 'pair-tested' males (Nos 68, 62, 64 and 66) and 780 30-min samples of behaviour of Males 57 and 59 (Groups A and B, respectively). Vaginal smears were taken between 16.00 and $18.00 \mathrm{~h}$ daily (although some days were missed before 1 June, 1974), as well as immediately after each observation session in which copulation occurred. Vaginal cytology data are not reported here, but the smears were used to confirm observed ejaculations and to detect unobserved matings in Groups A and B. Blood samples were collected from Females 50, 54, 51 and 55 between 16 September and 11 October 1974. The blood was withdrawn, between 12.00 and $14.00 \mathrm{~h}$, from the saphenous vein while the untranquillized female was gently held in a restraint device. The females voluntarily entered the tubular Plexiglas restraint device for pieces of banana, and were accustomed to the procedure which had been followed daily for the previous 9 months to obtain vaginal smears.

The concentrations of progesterone were measured by radioimmunoassay (Karsch, Krey, Weick, Dierschke \& Knobil, 1973). The specificity of the antiserum (IHT-R11-7) obviated the necessity for chromatography. With $50 \mu \mathrm{l}$ aliquots of plasma the limit of sensitivity equalled $0.2 \mathrm{ng} / \mathrm{ml}$, the recovery of $\left[{ }^{14} \mathrm{C}\right]$ progesterone was $87 \pm 0.6 \%$, and the interassay coefficient of variability was $11 \cdot 7 \%$. Each assay of squirrel monkey progesterone was performed in duplicate without knowledge of the animal.

The males were weighed at 2-week intervals throughout the study to give an index of the 'fatted male' phenomenon (DuMond \& Hutchinson, 1967; Nadler \& Rosenblum, 1972). 


\section{Results}

\section{Copulatory behaviour}

In this study the overall incidence of copulation was very low: the 4 'pair-tested' males ejaculated in 47 of 1493 tests (range: 2 out of 366 tests to 20 out of 382 tests). The low incidence was not a function of brief-encounter tests because Male 57 in Group A ejaculated on only 12 of 393 days (spermatozoa in vaginal smears) and Male 59 in Group B ejaculated (with conception) on only 1 of 387 days.

To attempt copulation the male approaches, clasps the female's waist and attempts to position his body for intromission. The hind feet may clasp the female's tail (pushing it sideways), the female's ankles or just the perch. Copulation was invariably attempted when the animals were precariously perched on a 4-cm diameter metal rod extending the depth of the cage, and hence the movements and position of the female could facilitate or hinder the male's intromission attempts.

Characteristics of the 39 copulations with ejaculation observed in the present study are shown in Table 1. Copulation usually consisted of only a single mount series to ejaculation, and only one or two mounts with intromission. In no case was there a second ejaculation in the 30-min encounter, although the males usually achieved ejaculation early in the test period: in $85 \%$ of the tests the male did not resume mounting after ejaculation, and in the 6 tests in which he did (4-18 min later) intromission was never achieved. The male initiated $89 \%$ of the 216 mounts in the 39 tests, the remaining 24 mounts being initiated by the female who postured by raising her perineum toward the male's face and looking back, or crouching in front of the male with thighs spread and looking back at the male (Latta et al., 1967; Baldwin, 1968, 1971).

Table 1. Quantitative description of copulatory behaviour of male squirrel monkeys in 39 30-min tests in which ejaculation occurred

\begin{tabular}{lcc}
\hline & Mean \pm S.E.M. & Range \\
\hline $\begin{array}{l}\text { Total no. of mounts to ejaculation } \\
\begin{array}{l}\text { No. of mounts with intromission } \\
\text { before ejaculation }\end{array}\end{array}$ & $5 \cdot 31 \pm 0.94$ & $1-29$ \\
$\begin{array}{l}\text { No. of thrusts without intromission } \\
\text { before ejaculation }\end{array}$ & $1.59 \pm 0.21$ & $1-8$ \\
$\begin{array}{l}\text { No. of thrusts with intromission } \\
\text { before ejaculation }\end{array}$ & $25.05 \pm 3.96$ & $0-118$ \\
$\begin{array}{l}\text { Time to ejaculation (min) } \\
\text { No. of refusals by female per test }\end{array}$ & $20.61 \pm 1.68$ & $2-46$ \\
\hline
\end{tabular}

\section{Oestrous cycle}

Ejaculation never occurred on more than 2 consecutive days, but did occur on 2 successive days in 6 cases. When the oestrous cycle was considered to be the interval between ejaculations, excluding the second consecutive day, there were 33 intervals of 7-11 days duration, 4 of 18-20 days and 5 intervals were $25-200$ days duration. The median and modal length was 8 days $(n=42)$. For 36 oestrous periods there were $5.4 \pm 0.9$ (S.E.M.) mounts per test on Day E (=the first day of ejaculation) and $2.4 \pm 1.6$ mounts per test on Day $E+1$. On all other days there were virtually no mounts. The greatest number of mounting attempts also occurred on Days $\mathrm{E}$ and $\mathrm{E}+1$ (Text-fig. 1). Females refused the mounting attempts throughout the cycle, but the lowest proportion of refusals occurred on Days E and E + 1 (Text-fig. 1).

During the period when blood samples were taken, Females 50,51 and 55 did not copulate, but Female 54 had three successive 8-day oestrous cycles in which ejaculation and mounts occurred only on Day E, and 8 and 5 refusals occurred on Day E-1 in 2 of the 4 oestrous periods. The changes in plasma progesterone levels throughout these three oestrous cycles are shown in Text-fig. 2. 


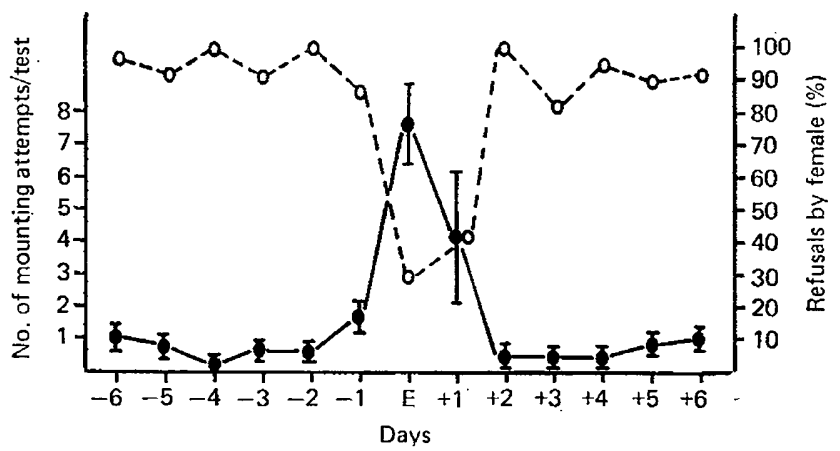

Text-fig. 1. Mean numbers ( \pm S.E.M.)/test of total mounting attempts $(\bullet)$ and $\%$ refusals by the female of the mounting attempts of the male $(O)$ for each day of the oestrous cycle ( 36 cycles). E refers to the day of ejaculation.

In each cycle there was a drop in progesterone concentration 2 days before the day of oestrus. The 3 females which did not copulate had markedly lower levels of progesterone $(4 \cdot 6-15 \cdot 4 \mathrm{ng} / \mathrm{ml})$ and there was no cyclic pattern.

\section{Annual changes}

Copulations first occurred soon after the study began, during the 3rd week of November 1973, and $95 \%$ of the 60 days of ejaculations were recorded during the following August-February (Text-fig. 3). Male 59 ejaculated only once, on 13 December 1973, and a male infant was born to Female 44162 days later on 23 May 1974. The length of the mating 'season' of each male (excluding Males 59 and 64 which ejaculated only once) was $19 \cdot 7$ weeks (Male 66), 6.8 and 15.7 weeks (Male 68), $7 \cdot 7$ and 11.8 weeks (Male 62) and 10 and $10 \cdot 4$ weeks (Male 57).

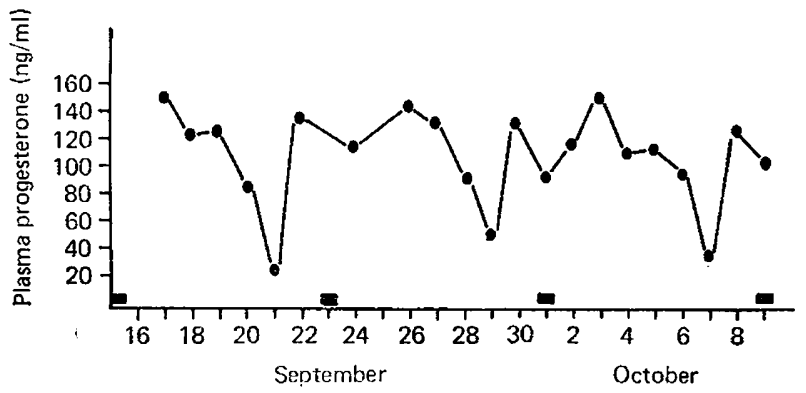

Text-fig. 2. Changes in plasma progesterone levels throughout 3 oestrous cycles of one female squirrel monkey (No. 54). The day of oestrus is indicated by the horizontal bar.

Male mounts showed some annual cyclicity: $79 \%$ of 435 mounts by the 6 males occurred between August and February (65\% of the observation period). One male (No. 66) was responsible for $86 \%$ of the 91 mounts which occurred 'out of season' from March to July. Female refusals of male mounting attempts were not limited to any particular period of the year: $64 \%$ of 979 refusals occurred between August and February.

Because of large individual differences in body weight and because of linear growth trends due to improved health after arrival from Peru, the body weight data were expressed as \% deviations from individual linear regressions (Text-fig. 4) and averaged for the 6 males. All males except No. 68 showed a peak in body weight in August 1974, the beginning of the 'mating season'. The average weight for the year for the 6 males was $971.7 \pm 35.5 \mathrm{~g}$, compared with that of $1075.8 \pm 32.7 \mathrm{~g}$ in August. 


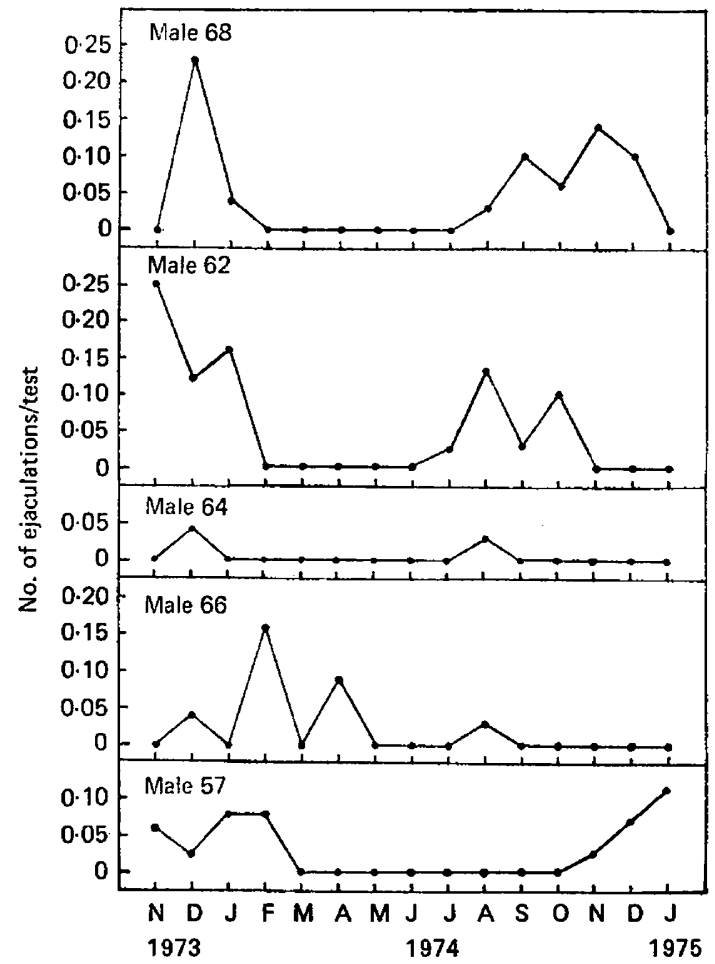

Text-fig. 3. Annual changes in mean numbers of ejaculations per test for 5 squirrel monkey males. Males $68,62,64$ and 66 were 'pair-tested' and Male 57 was a member of resident Group A. Data based on 364-393 30-mm observation sessions per male.

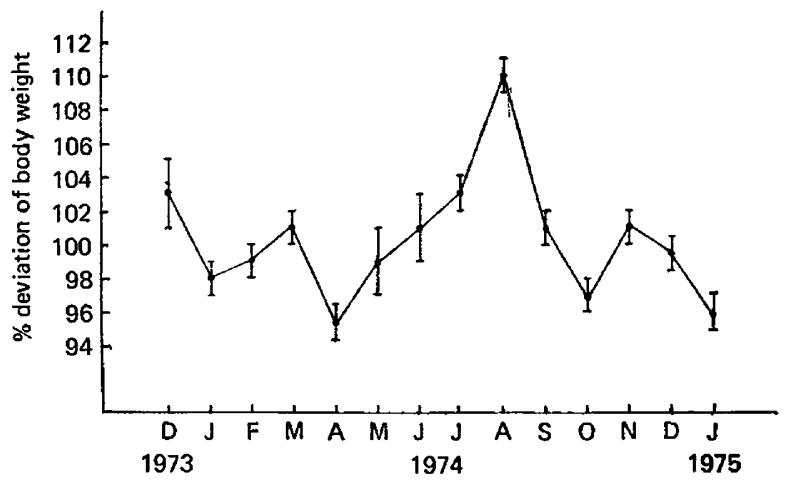

Text-fig. 4. Annual changes (mean \pm S.E.M.) in body weight of 6 male squirrel monkeys weighed at 2-week intervals.

\section{Discussion}

The reproductive cycle of the female squirrel monkey is characteristic of an oestrous cycle rather than a menstrual cycle which occurs in Old World monkeys and apes (Butler, 1974), because there is no menstrual bleeding and the female accepts coitus only during a limited period of behavioural receptivity. In the present study, the sexual behaviour of the male was used as an index of the sexual attractiveness and receptivity of the female. Successful mounts occurred on only 2 days of the cycle, and mostly on only 1 day. Mounts attempted on other days were refused by the females. There 
were no obvious and reliable indices of oestrus other than the occurrence of mounts and intromission resulting in ejaculation. Slight swelling of the external genitalia of the female was occasionally observed (Wilson, 1977) but this was not a reliable indicator of behavioural oestrus. A copious thick white vaginal discharge (Wilson, 1977) lasting for 1-2 days was recorded on 17 occasions and sometimes (5 occasions) occurred 2-4 days after copulation and ejaculation, but it was never a reliable index of behavioural oestrus, contrary to the apparent association with vaginal oestrus (Lang, 1967; Clewe, 1969; Srivastava et al., 1970; Travis \& Holmes, 1974).

The 8-day median and modal length of the oestrous cycle determined in this study is in accord with other reports of an 8-13 day cycle (Lang, 1967; Rosenblum et al., 1967; Hutchinson, 1970; O'Connor \& Wolf, 1971; Travis \& Holmes, 1974). The squirrel monkey therefore appears to have a short oestrous cycle, unlike that of other primates (except Tupaia, Sorenson \& Conaway, 1968) which exhibit oestrous cycles (Butler, 1974). In this they also differ from other Cebidae (Cebus and Ateles, Butler, 1974), and from Old World monkeys and apes which generally have menstrual cycles of about 30 days duration (Butler, 1974).

The plasma progesterone levels in Female 54 were similar to those reported by O'Connor \& Wolf (1971) and the peak levels were about 6-25 times higher than those found in Old World monkeys (Knobil, 1973; Eaton \& Resko, 1974; Resko, Koering, Goy \& Phoenix, 1975), and the prosimian, Galago crassicaudatus (Eaton, Slob \& Resko, 1973). The New World marmoset, Saguinus oedipus, has peak plasma progestin levels of $221-326 \mathrm{ng} / \mathrm{ml}$ ( 5 females) every 15 days (Preslock, Hampton \& Hampton, 1973) and very high plasma hormone levels may be characteristic of New World monkeys.

The squirrel monkeys in the present study exhibited very low levels of sexual activity, 60 ejaculations by 6 males occurring on only 60 days in 14 months. Comparable procedures with rhesus monkey females with ligated oviducts and daily mating tests for 1 year gave much higher levels of sexual activity; 1.3 to 2.3 ejaculations per test throughout the year (Michael \& Keverne, 1971). Baldwin (1968) reported only 13 ejaculations in 26 mounts in semifree-ranging squirrel monkeys in Florida during a 13-month period, and (1971) that only 3 or 4 females out of 41 were sexually receptive at one time.

The behavioural events immediately preceding ejaculation, several mounts with unintromitted and intromitted thrusts, as described in this study, are for the most part similar to other descriptions of copulation in squirrel monkeys. Baldwin (1968) noted that ejaculations among semifreeranging animals were preceded by 4-5 mounts, and that there were 13-14 sec of pelvic thrusting per mount. The animals studied by Latta et al. (1967), however, took many more intromissions to ejaculation: 4 ejaculations were preceded by an average of 16 mounts of which 13, on average, were characterized by slow 'intromitted' thrusts. An accurate count of unintromitted thrusts in the present study was sometimes impossible when the thrusting movements were rapid and shallow, and only numbers of discrete thrusting movements were recorded. The unintromitted penis could often be seen, and the changing orientation of the pelvis was also an indication of the lack of intromission.

The 'mating season' of individual males in this study extended for 6.8 to 19.7 weeks, which compares well with that of 8-12 weeks for semifree-ranging squirrel monkeys (DuMond \& Hutchinson, 1967; Baldwin, 1968). In Peru, the mating season of squirrel monkeys extends through July and August (DuMond \& Hutchinson, 1967; Baldwin \& Baldwin, 1971). My animals, shipped from Peru during the mating season, exhibited a surprisingly early first laboratory 'mating season': November through February. The novel social milieu of the animals' initial social encounters may have stimulated sexual activity. Clewe (1969), Lang (1967), Hutchinson (1970) and Travis \& Holmes (1974) have all reported frequent mounts when groups of squirrel monkeys are first formed and much social excitement is apparent. The second laboratory 'mating season', starting in August, coincides with the Peruvian season. There was an August peak in male body weight (the 'fatted male' phenomenon), which likewise occurs seasonally in free-ranging squirrel monkeys (DuMond \& Hutchinson, 1967) and is testosterone-dependent (Nadler \& Rosenblum, 1972). The constant 12-h light-dark cycle and temperature of $24.4^{\circ} \mathrm{C}$ in which my animals were kept are comparable to conditions at Iquitos (DuMond \& Hutchinson, 1967). Humidity varied in the laboratory, but was maximal in summer, whereas in Peru summer is the dry season. Only long-term study can reveal whether the August mating and 'fatting' observed in the laboratory are due to a circennial rhythm. 
This work was supported by grants from the Population Council and the National Research Council of Canada (A9803). The plasma progesterone assays were conducted in Dr E. Knobil's laboratory, Department of Physiology, University of Pittsburgh School of Medicine, Pennsylvania. I thank Keith Doan for research assistance and Martin Daly for critical comments on the manuscript.

\section{References}

BALDwIN, J.D. (1968) The social behavior of adult male squirrel monkeys (Saimiri sciureus) in a seminatural environment. Folia primat. 9, 281-314.

BALDwIN, J.D. (1970) Reproductive synchronization in squirrel monkeys (Saimiri). Primates 11, 317-326.

BALDWIN, J.D. (1971) The social organization of a semifree-ranging troop of squirrel monkeys (Saimiri sciureus). Folia primat. 14, 23-50.

Baldwin, J. D. \& BALdwin, J. (1971) Squirrel monkeys (Saimiri) in natural habitats in Panama, Colombia, Brazil and Peru. Primates 12, 45-61.

ButLeR, H. (1974) Evolutionary trends in primate sex cycles. Contrib. Primat. 3, 2-35.

Clewe, T.H. (1969) Observations on reproduction of squirrel monkeys in captivity. J. Reprod. Fert., Suppl. 6, 151-156.

Denniston, R.H. (1964) Notes on the vaginal cornification cycle of captive squirrel monkeys. J. Mammal. 45, 471 .

DuMond, F. \& Hutchinson, T.C. (1967) Squirrel monkey reproduction: the 'fatted' male phenomenon and seasonal spermatogenesis. Science, N.Y. 158, 1067-1070.

EAton, G.G. \& Resko, J.A. (1974) Ovarian hormones and sexual behavior in Macaca nemestrina. J. comp. Physiol.Psychol. 86, 919-925.

EAton, G.G., Slos, A. \& Resko, J.A. (1973) Cycles of mating behaviour, oestrogen and progesterone in the thick-tailed bushbaby (Galago crassicaudatus crassicaudatus) under laboratory conditions. Anim. Behav. 21, 309-315.

Hopf, S., Hartmann-Wiesner, E., Kühlmorgen, B. \& MAYER, S. (1974) The behavioral repertoire of the squirrel monkey (Saimiri). Folia primat. 21, 225-249.

Hutchinson, T.C. (1970) Vaginal cytology and reproduction in the squirrel monkey (Saimiri sciureus). Folia primat. 12, 212-223.

Karsch, F.J., KreY, L.C., Weick, R.F., Dierschke, D.J. \& KNOBIL, E. (1973) Functional luteolysis in the rhesus monkey: the role of estrogen. Endocrinology 92, 1148-1152.

KLEIN, L.L. (1974) Agonistic behavior in neotropical primates. In Primate Aggression, Territoriality, and Xenophobia, pp. 77-122, Ed. R. L. Holloway. Academic Press, New York.

KNOBIL, E. (1973) On the regulation of the primate corpus luteum. Biol. Reprod. 8, 246-258.

LANG, C.M. (1967) The estrous cycle of the squirrel monkey (Saimiri sciureus). Lab. Anim. Care 17, 442451.
Latta, J., Hopf, S. \& Ploog, D. (1967) Observation on mating behavior and sexual play in the squirrel monkey (Saimiri sciureus). Primates 8, 229246.

Michael, R.P. \& KeVerne, E.B. (1971) An annual rhythm in the sexual activity of the male rhesus monkey, Macaca mulatta, in the laboratory. $J$. Reprod. Fert. 25, 95-98.

Nadler, R.D. \& Rosenblum, L.A. (1972) Hormonal regulation of the "fatted" phenomenon in squirrel monkeys. Anat. Rec. 173, 181-188.

O'ConNoR, R.F. \& Wolf, R.C. (1971) Seasonal fluctuation in plasma progestins of the squirrel monkey. Am. Zool. 11, 649.

Preslock, J.P., Hampton, S.H., \& Hampton, J.K. (1973) Cyclic variations of serum progestins and immunoreactive estrogens in marmosets. Endocrinology 92, 1096-1101.

Resko, J.A., Koering, M.J., Goy, R.W. \& Phoenix, C.H. (1975) Preovulatory progestins: observations on their source in rhesus monkeys. J. clin. Endocr. Metab. 41, 120-125.

Rosenblum, L.A. (1968) Some aspects of female reproductive physiology in the squirrel monkey. In The Squirrel Monkey, pp. 147-169. Eds L.A. Rosenblum \& R.W. Cooper. Academic Press, New York.

Rosenblum, L.A., Nathan, T., Nelson, J. \& Kaufman, I.C. (1967) Vaginal cornification cycles in the squirrel monkey (Saimiri sciurea). Folia primat. 6, 83-91.

Sorenson, M.W. \& Conaway, C.H. (1968) The social and reproductive behavior of Tupaia montana in captivity. J. Mammal. 49, 502-512.

Srivastava, P.K., Cavazos, F. \& Lucas, F.V. (1970) Biology of reproduction in the squirrel monkey (Saimiri sciureus). I. The estrous cycle. Primates 11, 125-134.

Thorington, R. W. (1968) Observations of squirrel monkeys in a Colombian Forest. In The Squirrel Monkey, pp. 69-85. Eds L.A. Rosenblum \& R. W. Cooper. Academic Press, New York.

Travis, J.C. \& Holmes, W.N. (1974) Some physiological and behavioural changes associated with oestrus and pregnancy in the squirrel monkey (Saimiri sciureus). J. Zool., Lond. 174, 41-66.

Wilson, M.I. (1977) A note on the external genitalia of female squirrel monkeys (Saimiri sciureus). J. med. Primat. (in press). 